\title{
THE DECAY OF STATE AND LOCAL GOVERNMENTS.
}

Among the many political changes which have occurred during the history of the American people, there are few that can compare in importance with the growth of the national feeling by which the state and local governments have lost their former independent position and are now valued largely for the places they furnish for partisans of national politics.

In the greater part of our country, governors, legislators county officials, and even town constables and collectors are not chosen because they have an individual policy, or because they have, in the estimation of their fellow citizens, an especial fitness for the office they seek. Their only claim for preferment rests upon the services they have rendered the national party of which they are members. They do not ask for support because of some local measure they wish to enforce, or because of a better economy of the public revenues with which they will be entrusted. Voters do not usually question office seekers about such matters. They merely demand that the candidate be sound upon the tariff, reconstruction and other national issues, and if his views coincide with theirs upon these points he is sure of their ballots.

The average voter of to-day would have been a puzzle to our ancestors. The motives upon which he acts would seem incomprehensible to them. They looked upon the state as a sovereign, and kept state issues independent of those of the nation. They limited the power of the nation as much as possible, with the hope that the states would 
retain their vitality and be the real centre of power and influence. They took the same care to see that the activity of the towns was not abridged, knowing that the local governments are the best school for the education of the voter. Each part of our really complex system of government had a meaning to them, and they exerted the utmost vigilance to insure that no part lost its vitality. Nothing could have grieved the fathers of our country more than to know that before the end of the first century of our national existence, state and local governments would have sunk to their present condition, with a mere nominal existence.

Surely this change is not without a cause. There has certainly been some defect either in the spirit of the people or in the plans of our ancestors. To discover the source of this change should be of interest to every patriotic citizen, and I wonder that the subject has attracted so little attention even from those who know our history best. We have accepted the change as readily as though it was the very result our fathers most desired, and have never felt the need of asking anyone for an explanation. Yet the cause of all this is not obscure if we look in the right place for it. The framers of our institutions overlooked a few simple facts, and from the fruit of their mistake we now suffer. A single error is often able to undo the effects of many wise acts and prevent the execution of the ablest plans.

First of all, the question arises whether our present political evils come from a decay of moral tone and public spirit, or from certain mechanical defects in our system of government through which our legislative bodies reflect the views and sentiments of the less progressive instead of the more progressive part of the public. If the legislator represents the latter, any change in the mechanism of our political system would be of no avail. The only hope of progress would then lie in checking the influence of the degrading tendencies in our present economic and social environment, and in educating the public up to higher moral and political standards. 
I should emphasize the need of work in this direction as much as anyone could; yet before relying solely upon these means for the promotion of worthy ends, we should feel sure that any advance in public opinion will find expression in the law-making bodies. If a defective mechanism prevents an adjustment of our laws to the requirements of a progressive society, we must improve this mechanism before an orderly progress is possible. In short, does the progressive part of society have its wishes reflected in the acts of our legislatures? Are our penal laws, our school system, our sanitation and our civil service in harmony with the ideas of those who are the best judges of what the public needs? If legislation lags behind public opinion, the mechanism, and not the spirit of our institutions, is at fault. Some of our states have intelligent citizens, and in them we might expect new plans and measures to have a trial before coming into general use. Model states have in the past exerted great influence on national life, and the present lack of such states is a great barrier to progress.

Do we not need to seek a cause for these changes, and can they be properly explained by any supposed lowering of the moral tone or public spirit of the American people? Surely the problem involved in these questions is worthy of earnest consideration.

Let us then examine the circumstances surrounding the early American colonists to see what causes gave so much vitality to their institutions. The settlers did not come as individuals, each acting for himself. They came in groups of many families and often by shiploads, held together by religious or by national ties. Whole congregations from the mother country, dissatisfied by religious intolerance, came at the same time and settled around some centre where they might enjoy their rights without disturbance. So, too, people from the same nation, province or town naturally held together and settled in the same locality. When the regions farther from the coast were occupied the same plan was followed. We often hear of whole congre- 
gations moving to some new locality where better prospects were presented. Even where no formal agreement was made, some settler led the way to a new region, and around him grew up a little village composed mainly of his friends who had followed him from the old home. The earnest desire for church privileges naturally induced families of a common faith to settle near one another. They created a village near their church, which became the seat of their local government. As population became more dense new villages sprung up between the older ones and became independent in their political life. There were no fixed lines which determined the limits of towns. The colony was divided into towns according to the convenience of the people, and these towns were again subdivided as soon as the need of new centres was felt. This process of natural development was continued throughout the settlement of the Atlantic States. Each town in this region became a centre of a group of families having common aims and interests which bound them together in a real unit.

When, however, the settlement of the Mississippi Valley began, a new plan for the formation of towns was adopted. The general government surveyed the whole country and laid it out into townships six miles square, each of which was organized as a civil town. This method stopped that natural growth of towns which had been so successful on the other side of the Alleghanies. Groups of settlers having common interests were no longer allowed to form local governments suited to their needs. They found the town line run through the middle of their settlement, which forced them to enter into a civil town with strangers with whom they had no common interests. An arbitrary line drawn by a surveyor, before any settlements are made, has no regard for the feelings or social ties of the settlers. The inhabitants of each six miles square are forced into an unnatural unit, where there is no possibility of creating a real bond of union. They come from different sections of our country and have different ideas as to what local gov- 
ernment should be. People from New England, Pennsylvania and Virginia find themselves thrown into one town, and among them are sprinkled the Irish, Germans and other classes of immigrants. Such an aggregate cannot agree upon measures of common interest. Lovers of good roads find for neighbors those who think the natural soil makes a good enough highway for them, even if at times a team cannot draw an empty wagon over it. Friends of good schools are outvoted by those who regard a single term in a log cabin as enough schooling for their children. And then to increase the discord, the railroads do not follow the surveyor's lines and run through the centre of each town. They follow the track which the natural features of the country dictate and place their stations without regard to town lines. As a result two or more villages grow up in one town and in the next the farmers are divided into several sections, each going in different directions to the nearest market. The different villages and sections thus continue strangers to one another, only meeting on election day. Such an abnormal unit destroys the conditions of local government and saps its vitality. The farther west we go the more do these and other similar causes operate, and as a result the town loses its independence and becomes a mere election precinct.

If we turn to the development of the states, we find that these causes have produced the same disadvantageous results. The old colonies grew up having common bonds of religion or of descent holding together their inhabitants. Massachusetts, New York, Pennsylvania, Virginia and the Carolinas each stood for a special kind of civilization which gave them unity and awoke in their inhabitants common ideas which the state could realize. They were real commonwealths which protected their citizens and aided them in their development. The western states have no such origin. They were laid out before they were inhabited, and have rivers, lakes, or, even worse, lines of latitude and longitude for their boundaries. Of course, such a method 
is an easy way to divide up a new country, but no worse way could be devised for making states. Rivers and lakes are the natural means of transit and should be in the centre of states. Nothing could be more arbitrary than to make the Ohio and Mississippi Rivers state boundaries. The two slopes of these rivers have a similar climate. Their inhabitants have the same centres of trade, and migrating from the same states have similar ideas as to education and government. The same facts are true of the regions about the lakes. And yet our forefathers disregarded all these considerations and threw together the most discordant elements into one state. How could the dictates of reason and experience be more rudely set aside than they were when Ohio, Indiana and Illinois were formed ? The northern and southern halves of these states have distinct climates and are fitted by nature for a very different series of crops. Add to this the fact that they were settled by two distinct currents of immigration-the one from New England and the other from the south-and what can be expected but that these states should be merely inharmonious units out of which can grow none of those common feelings which are needed to give vitality to state institutions?

There is yet another cause which has done much to prevent the growth of local government in these states. The first settlers were scattered so thinly over the whole region that sufficient population to make a state could not be secured without including an enormous area in the state. Had the process of forming states proceeded more slowly, the states could have been made smaller and yet they would not have lacked in population. Doubtless, too, the desire of the east to retain control of the national senate also contributed much toward increasing the size of the newer states. Perhaps the desire to be a powerful state exerted an influence in the same direction. The real functions of state government are so little appreciated that many persons are attracted more by the idea of a powerful state than by that of a useful state. 
The combined result of these causes has made all the western states too large. The farther west we go the larger have the states been made, and, as a result, the less has become the vitality of local institutions. They are empires which cover so great a stretch of land that they contain soils and climates of the most dissimilar character. Local feeling cannot develop under these conditions. It needs the fostering influence of a common climate and soil, coupled with a common ancestry, to develop in each community those local usages and sentiments which give vitality to its government. Put the boundary of each state so as to include within it only a few varieties of soil and climate cultivated by men having similar ideas and tendencies, and the conditions for an active government are secured. Disregard these conditions by putting navigable rivers or lakes on the boundaries of states instead of at their centres, and the soil and climate will be so dissimilar that even a people of common ancestry will soon develop such differences in habits and ideas that no one government can satisfy the local wants of each section.

Illinois furnishes as good an example as we have of the evil effects which follow from a disregard of the necessary conditions of successful local government. In regard to climate, Illinois is divided into three distinct regions. The southern part is noted for its wheat and fruit, the central part forms a portion of the great corn belt, while the northern end, being a splendid grazing country, cannot be surpassed in its dairy products. Each of these sections was settled by a distinct class of immigrants. Those in the southern end came from Virginia and Kentucky, those in the centre from Ohio and Pennsylvania, and those in the north from New England and New York. Each of these sections also has its distinct market. The south has an outlet on the Ohio and Mississippi rivers, the north has the lake at Chicago, while the centre, through its many railroads, has direct intercourse with eastern cities. We thus find thrown together a region which ought from differences 
of soil, climate, market and people to be three states. Had three states been made, local institutions would have developed, and all those feelings which similar social and economic conditions bring out, would have been strengthened in such a way as to give the needed vitality to each state. As it now is, there is one unwieldy state, too large to perform the functions expected from a local government, and too small to be a sovereign state. The laws have to be enacted in so general a form that they are not suited for the purposes of the localities. The northern end wants the township government of New England. The southern end prefers to be governed solely by county commissioners after the model of the southern states. The people on the flat lands in the eastern part of the state ask that large drainage districts be formed in which all the land should be drained out of a general fund, while the rest of the state are opposed to compulsory drainage. Here the people would allow cattle free range; there they think cattle should be confined in fields so that the mass of cultivated fields need not be enclosed. In one county free whisky is desired. In the next nothing short of complete prohibition will satisfy the people.

In this way the whole range of local laws might be gone through with, showing how impossible it is to make any definite laws adapted to a state as large and diversified as Illinois. Even the criminal code cannot satisfy the demands of the various sections. The only way out of the difficulty is to enact optional laws and allow each community to decide which of these laws it desires. As soon, however, as a state becomes so large as to make this a necessity, it loses all those characteristics which are essential to a vigorous local government. It becomes merely a kind of national government. In fact, the legislature of Illinois, or that of any other large western state, could just as well legislate for the whole Mississippi Valley as for its own territory. Each state repeats the laws made by its neighbors in about the same words, and avoids as much as pos- 
sible any action of a local nature. Our state governments, having developed into a kind of national government, leave us without anybody to perform those functions which made the state of our fathers so useful to them.

The depression of political activity and of independence of voters is another detrimental result following the creation of large states. In a small state each town has its representative in the legistature, while in the large state several counties must often be thrown into one district to secure the requisite population. The representative of a small constituency is elected largely upon personal and local issues. Every one knows the candidates, and as their whole lives have been passed under the eyes of the voters, an official is not likely to be selected against whom serious objections can be raised. The candidate before a large constituency is judged from another position. He is personally known to but a mere fraction of the voters, and the rest learn of him through the papers or by means of large political gatherings, and at a time when their judgment is most biased by strong political feelings. Partisan papers and paid orators praise and denounce him for political ends, leaving the voter without any reliable means of information from which he may learn the truth. The voter becomes so accustomed to hearing every candidate accused of dishonesty, immorality, or crime, that he ceases to heed any warning and votes as his party feelings dictate. The growth of party spirit is the legitimate outcome of large constituencies. The people are not less intelligent than they formerly were. They are now, however, thrown under conditions where independent action is impossible. If an intelligent voter desires to defeat an unsuitable candidate he can exert a powerful influence over a community among whom he is well known. As soon as he seeks to influence strangers he is upon another footing. His face looks to them no different from that of other politicians, and his tale seems only a new edition of the old story of which they have heard so much and by which they have 
been so often deceived. He fails of his mission because he can offer no mark by which his story can be distinguished from the ordinary campaign slander. Against his word the candidate presents the sworn statement of twenty fellow citizens, and why is not the word of twenty strangers as good as that of the twenty-first?

The power of independent action is greatly diminished by the frequent changes in the boundaries of the districts. At best the same boundaries are retained but ten years, and they are changed as much oftener as the needs of the dominant party may dictate. Scarcely do the people learn the politicians in their district before a new distribution of seats brings a fresh lot within their boundaries. Even if the independent voters do succeed in a few districts the result is not bettered. In the legislature their candidate finds himself powerless unless he will act with the other members from his section of the state. When a state is composed of several distinct sections having peculiar wants, a majority can be secured only by some trading, by which the measures of other sections are voted for to secure their aid when it is desired. The members of each section neither know nor care for the wants of the rest of the state, and are willing to enter any combination to obtain what they wish or defeat what they dislike. If the state contains a large city a new element of discord is added, and a new basis of trading is secured ; the vitality of the parties in thus increased at the expense of that of the independent voters.

With these difficulties to contend against it is easy to see why the voters in the large states are so submissive to party dictation. It is not that they lack intelligence, nor is it because they are unwilling to act independently, or to work for public interest. It is because they are thrown together in such large districts that individual effort is of no avail. The united action of a few party leaders has a greater effect than the unorganized efforts of as many hundred individuals who are complete strangers to one 
another. No matter how zealous they may be, they soon become conscious that they are powerless, and give up in hopeless despair. Every success of party discipline strengthens the bonds which bind the people to the party, and causes the young men to grow up so submissive that they are proud of the yoke which binds them to their party.

I fear that there are too few who realize the difference between the young voters of to-day and their fathers, who received their political education before the war. It is the old men and not the young who make trouble for the party leaders. The former think as individuals, the latter act in herds ready to obey any command of the leaders. The great cause of this change lies in the decay of local government. In the western states at least the powers of the towns have been so abridged that local elections afford no opportunity to educate the young voter in the only field where he can act independently. State elections cannot now be classed as local elections. The smallest district, that electing a state representative, has more population than a congressional district had when our nation was formed.

Had the fathers of our nation recognized the true function of the states and not sought to make empires of them, the present evils of our political world could have been avoided. See how unskillfully even the Atlantic states were formed. The fertile low lands of the coast were united with the highlands of the Alleghany region. Each of the larger states is formed of two distinct regions differing widely in soil and climate, and occupied by people having different habits, customs and occupations. Had the South been formed into smaller states, with boundaries fixed where soil and climate demand, we would not be troubled by a Solid South. The colored vote lies in the low region along the coast and the great rivers. If the highlands had been separated from the low lands and made into states they would not be troubled with the negro problem, 
and might readily become progressive states. What, for example, could be more absurd than to unite east and west Tennessee in one state? It were far better to unite east Tennessee with western North Carolina. Then there would be three states with natural boundaries, in each of which local feelings would create a real state. Northern Alabama and Georgia have few interests in common with the southern portion of these states. Even if this region could have but two states, an east and west division line would be far better than a north and south one. In the same way it could be easily shown how all the southern states might be split up in a way that would localize the evils from which they suffer, and allow progressive regions to develop according to their inclinations.

In that large region west of the Missouri, the errors of the past are being repeated and magnified. By admitting the territories, with their present boundaries, we have created great empires in which local institutions have no vitality. The representatives of the several sections of each state will meet at some centre to bargain and trade, and the independent voter will be as powerless as though he lived in Russia or China. Young men will be educated to think more of party than of principles, and will learn to take pride in the fact that they have never sacrificed the former for the latter. It is not enough to divide Dakota by an east and west line. The natural conditions of east and west Dakota are as dissimilar as those of north and south Dakota. The higher lands of the west differ radically in soil and climate from those of the east, and will develop a people with peculiar characteristics. In Montana the miners in the west need other local institutions from the herders of sheep and cattle in the east. Notice how the region around the Black Hills is thrown into different states, merely because certain geographical lines happen to run through them. Our statesmen seem to think that arbitrary straight lines, selected before the characteristics of the region were known, make better boundaries of 
states than do those conforming to natural features. Some of the states are even hung over the Rocky Mountains, just as though a useful state could be made out of a region separated by such a barrier. See how Colorado is formed, with a great agricultural plain at the east, united to large mineral regions at the west. Yet Kansas, Nebraska and Oregon will not be found any better if we take the care to seek out their local peculiarities. What local institutions and usages have we to hope for in states constructed in defiance of nature like those of Texas and California?

It may be said that the plan of these states is no worse than that by which the northern and southern parts of Michigan, Wisconsin and Minnesota are hitched together, and yet those states prosper. Certainly, and we should prosper also if all state lines were swept away. The material development of the nation will go on just the same whether it be cut up in large or small states. The difference will show itself in the political ideas of the people. Shall the young receive their political education at the party caucuses or at the town meeting? Shall they be taught to respect the rights of the minority or to glory in coercing them? The education of the caucus inculcates a spirit of intolerance and a desire to suppress, if not to defraud, the minority. In local affairs the evils of suppression and coercion bear their fruit too quickly to be concealed. The voter soon sees the limits of majority rule. No such evils are apparent when the effects are spread over a whole state and mixed in with the thousand other causes which make a state prosperous. The country will grow wealthy in spite of party rule, and hence many fail to realize the consequences flowing from the suppression of minorities. The large states are thus poor places in which to learn the true principles of political action. The suppressed minority may be hundreds of miles away. They are persons with whom the majority have less intercourse and commerce than they have with many portions of 
Europe. This growth of party power prevents any campaigns upon local issues. The people have no confidence in the enforcement of local measures, since party leaders will sacrifice them to gain an advantage in national politics. Had we small homogeneous states inhabited by people with common sentiments and education any proposed law could be tested upon a small scale before its application became general. This advantage is lost by making the states so large that each of them contains all the discordant elements which exist in the nation. The difficulties, for example, in the enforcement of liquor laws in Kansas are not less in number than for the whole nation. In fact, some of them would disappear if these laws were general. Under these conditions it is useless to hope that the advocates of any measure will be content to keep it local. Even before they can carry a single precinct they will have a national party in full operation. Nor can they be blamed for taking the only course open to them, while state boundaries are not located with the view of bringing homogeneous elements together.

The political problems which the American people have yet to solve do not relate to the general principles of our government. The founders of our nation were right in making vigorous state and local governments an essential part of their system. It is not the principles upon which they relied that have proved faulty, but the mechanism through which these principles act. The boundaries of a vigorous local government cannot be left to the accidental lines which a surveyor may run across our land, guided only by a compass and a measuring chain. The vitality of our states depends, not on these accidents, but upon the ties of race, habits and customs of the people, and upon the peculiarities of soil and climate. These circumstances cannot be determined until the region is settled and the social and economic conditions are fixed.

It is therefore the absoluteness of our boundary lines and the unchangeableness of the territorial extent of our 
states, that are the sources of the present degenerate tendencies in our politics and a cause of the subordination of the individual to party power. Instead of regarding the boundaries of our states as fixed and unchangeable, we should recognize that we are only beginning to get the data upon which to decide where the boundaries of states can be properly located. If our states are to be a vital part of our political system, each section of our land which has distinct physical, social or economic conditions should be carved out of existing states and given that independence needed to make its government reflect the sentiments of its inhabitants. A mining section should not be forced into an incongruous union with wheat growers, nor should the latter be united with a grazing or a fruit-growing region.

Perhaps the best indication of a forced union of discordant elements in one state lies in having a strong majority in one end pitted against another majority in the other. If such a state of affairs continues for a long time, it shows that the opposition of interests has a foundation in the social or physical environment of its inhabitants, and that new boundary lines are needed for social progress and political development.

Should the American people act upon this plan and create natural boundaries for each state, the vitality of state and local governments can be restored and the power of national parties in state and local affairs materially diminished, if not destroyed. A great part of the present political corruption and bribery results from the forced union of incongruous elements in one state. Put a 75,000 Republican majority in the country districts of New York in conflict with a like Democratic majority in the city, and there is an uncontrollable conjunction of causes degrading political life, corrupting voters and subordinating civil service to partisan ends. Put these discordant elements into different states, and the motive would be absent which leads to corruption and bribery. The Republicans 
could carry the state as easily as the Democrats could the city.

One more suggestion and I am done. A large part of the degrading influence of our politics comes from the relation of the large cities to the states in which they are located. The state and the city have so few common interests that the contact of the two lowers their moral tone and leads to bargains, trades and corruption. It might be well to imitate the example of the free cities of Germany and give an autonomy to our great cities equal or nearly so to that of the states. German cities might serve for a model for our cities, as the Grecian states did for our federal government. Had our forefathers foreseen the rapid growth of our cities, through which they exceed in population many of the states, some such provision might have been made for the concentration of industry and trade in large centres. Their failure to provide for this contingency does not lessen the need of its recognition nor diminish the benefit that would result from the separation of city and state governments. The interests of cities are as distinct from those of the states in which they are located as the interests of the states are from one another. If local interests create a necessity for local autonomy, surely our cities need more freedom from state control. By uniting New York and all the adjacent cities in one independent whole, subject to certain fixed constitutional restrictions, a most depressing influence in national politics would be removed, and causes set in operation which would in the end purify local politics. The power of local bosses depends much more upon the aid they get from national than from local politics. The influence of individuals grows as the power of parties diminishes.

The changes I have indicated do not demand any radical alteration either in our political system or in our political ideas. They relate merely to the mechanism by which our system is carried into effect and our ideas realized. We should not, therefore, hesitate to modify this mechanism so 
as to defend our institutions against dangers which our forefathers could not foresee. By so doing we neither impeach their credit nor detract from their intelligence and sagacity. On the contrary, whatever makes our institutions more successful and protects the individual from the coercion of organized parties, reveals the excellence of their work, and the wisdom of their acts.

Simon N. Patten. 